\title{
ACOMPAÑAMIENTO TERAPEUTICO A LXS PACIENTES QUE BUSCAN PAREJA UTILIZANDO APLICACIONES DE MÓVILES (O NO) ${ }^{1}$
}

\author{
Concepció Garriga i Setó ${ }^{2}$ \\ Miembro de Forum, IARPP, EMDR \\ Terrassa (Barcelona)
}

\begin{abstract}
Basandose en la teoría del apego según los desarrollos de Bowlby, Stern y Wallin que muestran que la necesidad de vinculación es primaria, que el apego seguro proporciona un puerto base a la criatura en crecimiento, que la forma adulta de apego seguro es la pareja, y que su búsqueda, según Bleichmar, es un módulo motivacional fundamental, la autora sostiene, mediante la exposición de un caso clínico, la necesidad de apoyar a lxs pacientes que en el curso de su tratamiento deciden buscar pareja (en ocasiones con el uso de apps para móviles).
\end{abstract}

Palabras clave: apego, módulo motivacional, sujeto agente, autorrealización.

Based on attachment theory according to Bowlby, Stern, and Wallin's developments that show that the need for attachment is primary, that secure attachment provides a home port for the growing child, that the adult form of secure attachment is the couple, and that its search is, according to Bleichmar, a fundamental motivational module, the author argues, through the presentation of a clinical case, for the need to support patients who in the course of their treatment decide to seek a partner (sometimes with the use of mobile apps).

Key Words: attachment, motivational module, subject agent, self-realization

English Title: THERAPEUTIC ACCOMPANIMENT TO PATIENTS WHO ARE LOOKING FOR A COUPLE USING MOBILE APPLICATIONS (OR NOT)

\section{Cita bibliográfica / Reference citation:}

Garriga, C. (2017). Acompañamiento terapéutico a Ixs pacientes que buscan pareja utilizando aplicaciones de móviles (o no). Clínica e Investigación Relacional, 11 (3): 530-536. [ISSN 1988-2939]

[Recuperado de www.ceir.info ] DOI: 10.21110/19882939.2017.110304

\footnotetext{
${ }^{1}$ Comunicación presentada en el marco de la VII Reunión Anual de IARPP-E en Barcelona, 31 de marzo-1 de abril de 2017.

${ }^{2}$ Correo de contacto: concegarriga@gmail.com, y sitio web: www.concepciogarriga.com
} 
El ideal freudiano de la persona adulta era la individualidad autosuficiente y la dependencia era considerada el extremo patológico (Benjamin, 1988, 1995).

La teoría del apego (Bowlby, 1969; Stern, 1985; Wallin, 2007) mostró que la necesidad de vinculación es primaria, que el apego seguro proporciona un puerto base a la criatura en crecimiento, que la forma adulta de apego seguro es la pareja (Coderch, Plaza, 2016), y que su búsqueda es un módulo motivacional fundamental (Bleichmar, 1997).

Personalmente, poder abandonar el duro ideal de la autosuficiencia (del psicoanálisis y del feminismo) y poder abrazar la humanidad del apego como necesidad humana básica fue un verdadero alivio en mi análisis y en mi vida.

Desde esta posición, atiendo el deseo de buscar pareja en mis pacientes para iluminarlo, alentarlo y acompañarlo con la máxima empatía y vitalidad de la que soy capaz, convencida de sus bondades terapéuticas si consiguen un buen encaje, y decidida a cuestionarlo, si no es así.

Con frecuencia creciente algunxs pacientes deciden utilizar aplicaciones de móviles como una herramienta para ampliar su rango de posibilidades de establecer relaciones personales. Yo misma (Garriga, 2015a, 2015b) ya hice una primera incursión al tema en un trabajo previo. Hoy deseo aportar material clínico de un acompañamiento a través de las vicisitudes de un proceso de búsqueda de pareja, que se inició en el uso de las aplicaciones cuando había agotado todos los otros contextos de relación.

La evolución de mi paciente se fundamenta en el trabajo de Aron \& Atlas (2015) que propone que, 'para lograr el principal objetivo terapéutico que es: "allí donde había objetos, habrá sujetos" (Benjamin, 1995), se requiere que pasemos de objetos de fatalidad a sujetos capaces de crear nuestro futuro'.

La noción de sujeto agente (Gentille, 2016), junto con la de reconocimiento mutuo (Bejamin, 1988) son básicas para una idea de pareja que permita la autorrealización de sus componentes (Ringstrom, 2014).

\section{Caso PEPA}

Pepa es una inteligente catedrática de economía de 40 años. Cuando la recibí, a los 31, se describió como emocionalmente inestable, y con una vida amorosa desgraciada. Sólo había tenido una relación, a los 24 años, con una persona que la decepcionó profundamente porqué mantenía una relación paralela con otra mujer. 
Pepa afirma desde el primer momento que desea establecer una relación íntima pero que teme que se repita que la persona no esté disponible para ella. Esta posición está fuertemente enraizada en ella porque no se ha sentido querida por su madre desde que recuerda, de manera que en su inconsciente relacional (o Conocimiento Relacional Implícito) no solo hay un vacío doloroso, sino una sutil historia de trauma de desarrollo (Bromberg, 2006, van del Kolk, 2014). Pepa es la mayor de dos hermanos y dos hermanas que se llevan un año entre si.

A pesar de estar muy bien colocada laboralmente, pese a su corta edad, cuando Pepa llegó no se sentía a gusto en su facultad, y planificó cuidadosamente un traslado a otra universidad, cosa que logró con muchos esfuerzos y sacrificios materiales. Su tesón junto con mi confianza en su valía y capacidad, le permitieron efectuar los múltiples requerimientos necesarios con éxito.

A Pepa, cuya familia vive a 150km de Barcelona, al poco tiempo de empezar el tratamiento, se le hizo claro su deseo de adquirir un piso en propiedad. Lo logró en cuestión de meses. En este proceso, se le planteó un tema de género, dijo: "Está claro que tengo que trabajar duro para pagar la hipoteca, pero, esto no es cosa de hombres?" En seguida se dio cuenta de que mezclaba la soledad de tener que hacer frente a solas a la cuestión de la vivienda, con su deseo de construir una familia y de poder gestionar estos asuntos de forma compartida; también pudo expresar que en la microcultura de su familia de origen, una compra así, le correspondería a su padre, aunque la realidad era que sus padres se habían establecido en dependencia de su abuela paterna -el abuelo había fallecido muchos años atrás-, y vivían muy amargados por ello, pero en ningún momento trataron de situarse como una familia separada. En cambio estaban colocados como víctimas de su tiranía y albergaban una esperanza vana de que en algún momento esta mujer les trataría mejor, a pesar de que nunca lo hizo ni lo ha hecho. Actualmente esta mujer tiene 101 años y los padres de Pepa siguen pendientes de ella. Pepa, por lo tanto, fue la primera en su familia en conseguir "una habitación propia" (como el título homólogo de Virginia Woolf) y esto la hizo reflexionar respecto a su mayor capacidad y sentirse orgullosa de si misma.

El sistema de pensamiento de Pepa a veces es muy masivo, muy de "todo o nada". En ocasiones le cuesta mantenerse en la complejidad. También adopta una actitud de acomodación patológica (Brandchaft, 2010) ante sus compañerxs. Teme que si sus deseos se hacen presentes, la relación se romperá. Se le hace difícil contemplar que desde el reconocimiento mutuo (Benjamin, 1988) pueda encontrar una posición dentro de la relación aunque tenga que sostener la tensión de la diferencia. 
En ocasiones recurre a lo que yo llamo pensamiento mágico, con frases tipo "yo no tengo suerte". En estos momentos, se permite "soltar" su agencia, que la tiene, y se abandona a un funcionamiento más primitivo, de gratificación inmediata, que suele traducirse en comer y posponer, con la justificación de que es el azar el que determina la dirección de su vida. Cuando le señalo esta posición de autoabandono, Pepa suele compartir mi visión y la modifica, es decir, coge las riendas de su agencia: dieta, citas, tareas pendientes... y entonces, adelgaza, queda con hombres, presenta trabajos,... hasta que algo la desanima, o la angustia y vuelve a surgir el pensamiento mágico. Van der Kolk (2014) lo explica diciendo que "generalmente el cerebro racional puede anteponerse al cerebro emocional, siempre y cuando nuestros miedos no nos secuestren. Pero cuando nos sentimos atrapadxs, furiosxs, o rechazadxs retrocedemos a modos de funcionamiento más arcaicos, que tenemos automatizados. El cambio empieza cuando aprendemos a 'adueñarnos' de nuestro cerebro emocional, es decir, cuando podemos soportar, atravesar y aceptar las sensaciones desgarradoras y dolorosas de la desgracia y la humillación, en lugar de anularlas y volver a nuestros automatismos".

A pesar de sus múltiples logros Pepa no se reconocía como persona valiosa y esto se traducía en actitudes de poco respeto hacia si misma. Entonces no podía avanzar en su deseo de encontrar pareja y formar una familia.

A efectos de claridad en la exposición abordaré estas dos problemáticas por separado, pero en la realidad del tratamiento el trabajo ha sido conjunto y en paralelo.

El módulo de autoestima (Bleichmar, 1997) de Pepa, en ocasiones está muy flojo. Lo que remite a los aspectos traumáticos de su infancia, debidos a las negligencias emocionales sostenidas. Pepa tiene muchos recuerdos de soledad, de momentos en que su madre no sabía escucharla, consolarla o ayudarla. Como cuando, con cuatro o cinco años, se da cuenta de que tiene las rodillas valgas y le dice a su mamá: "tendremos que ir al médico", sin obtener respuesta alguna de ella. En otra ocasión pasa días aterrorizada temiendo ser descubierta porque se le ha roto una maderita de una ventana. Finalmente no pasa nada, pero nos muestra el temor y la poca confianza en las que vive. Otra escena es que ante sus angustias por un examen, su madre le suelta "ibasta de lamentaciones: si te angustias, dejas de estudiar y punto!". En estas situaciones ella se va haciendo pequeñita y siente que no es importante! Estas vivencias tienen lugar en un contexto en que lo que cuenta es el sufrimiento de los padres respecto a la abuela y los tíos. Un contexto, en que lo importante es la soledad de su madre. Un contexto en que lo que le sucede a ella es menor, no merece consideración alguna. expresa. Este material es para uso científico y profesional exclusivamente y puede contener información clínica sensible. Los editores no se responsabilizan de los contenidos de los autores. Dirigir las consultas sobre derechos y autorizaciones a ceir@psicoterapiarelacional.es 
Pero esto es el principio de la vida de Pepa, lo terrible es que estas situaciones se volverán a dar en otros momentos evolutivos. Cuando se enamora, y este hombre tiene otra novia. Cuando se siente excluida de su círculo de amigas porqué tienen visiones distintas de la vida.

\section{Encontrar pareja}

Coderch y Plaza (2016) afirman que desde un punto de vista psicoanalítico el deseo de constituirse en pareja responde a dos motivaciones esenciales: la necesidad de estructura de acogida y la motivación de apego seguro que incluye la necesidad de amar y ser amadx.

La gran tarea con Pepa ha sido el trabajo con el apego (Wallin, 2007). Pepa ha sostenido desde el principio del tratamiento que su deseo es formar una familia y tener hijos. A pesar de ello durante años ha tenido una fuerte ambigüedad respecto a las relaciones íntimas: por un lado las deseaba, mientras que por el otro la remitían a sufrimiento, por sus propias vivencias anteriores, así como por el modelo negativo de relación que ha visto en sus padres. Su madre, no solo supeditada a su padre, sino también a la madre de su padre. Pepa no desea de ninguna manera tener una vida que se parezca en nada a la de su madre. El reto para ella es poder construir una relación en la que ella tenga un lugar (Ringstrom, 2014), donde no tenga que desaparecer como persona.

Además Pepa siente la llamada del reloj biológico. Contempla embarazarse en solitario con técnicas de reproducción asistida de fertilización in vitro. También considera la posibilidad de adoptar. Antes de emplearse a fondo en alguna de estas vías desea darse una nueva oportunidad de conocer a alguien y explorar nuevos contextos relacionales: asiste a cursos mixtos (como catas de vinos, o escenarios gourmets), realiza actividades deportivas (excursiones por el campo en grupo, a caballo, andando,...). Aunque le resulta muy difícil de compaginar con su vida profesional hiperexigente: de preparación de clases y presentaciones, de proyectos de investigación y publicaciones...y no le permite la asiduidad necesaria para establecer algún vínculo.

Sus amigas se han metido en aplicaciones de móviles. A ella no le atrae la idea y sigue intentando las vías más convencionales. Pero cinco años después de haber iniciado la terapia, y viendo su poco avance, empieza a contemplar las aplicaciones de la época: Meetic, Vadoo,... que descarta. Se inclina por plataformas más sociales, que organizan actividades y salidas en grupo, con el objetivo secundario de conocer a alguien, tipo: "Gente como tú", "Meet up", ... y empieza a acostumbrarse a acudir a sitios en los que no conoce a nadie, y a quedar con personas que no ha visto nunca antes... 
Entretanto se somete a una intervención para la extracción de óvulos propios, que conserva congelados, mientras esperan la ocasión de ser fertilizados, con esperma de su pareja o de un donante.

Sus amigas le hablan de Tinder, una aplicación dinámica y fresca, y, hace dos años, se anima a probarla. Pasa temporadas largas teniendo citas con hombres de muy diversa índole, con períodos de desanimo por los pocos contactos interesantes que obtiene; pero persiste porque admite que no tiene otra opción si realmente desea encontrar a alguien. Yo la acompaño incansablemente en sus vaivenes emocionales relacionados con sus encuentros y desencuentros, hasta que se estabiliza con uno con quien pasará un año de altibajos. La voz del poeta (Josep Palau i Fabre) divulgada por la cantante (Ma. Del Mar Bonet) describe perfectamente la situación emocional de Pepa ante este hombre:

$$
\begin{aligned}
& \text { "Yo me daría a quien me quisiese, } \\
& \text { como si ni yo me diera cuenta: } \\
& \text { como una limosna que se me hiciera" }
\end{aligned}
$$

Pepa queda vinculada a él porqué, aunque poco, de él recibe más que de otros, menos presentes aún. Al final de este año de tiovivo emocional Pepa está emocionalmente desgastada, pero consigue alejar a este hombre mientras sigue explorando otras posibilidades.

Hace un año largo Pepa conoció a alguien con quien ha establecido un contacto progresivo y cada vez más satisfactorio, pero ha tenido que trabajar para salir de la ambigüedad de sus múltiples visiones de él (que es una persona que le da paz, que no tiene estudios superiores, que lo siente comprometido, que su presencia es sólida emocionalmente). Ha encontrado a una persona sin ataduras, disponible, con trabajo y también deseosa de construir una familia pequeña. Seguimos trabajando en esta vinculación de apego seguro que se está constituyendo en estructura de acogida en la justa medida en que ella desea. Está en las manos de Pepa marcar los tiempos y las direcciones! Efectivamente, en esta relación ella tiene un mayor peso específico, sólo tiene que jugarlo!

\section{REFERENCIAS}

Aron, L. \& Atlas, G. (2015). Generative Enactment: Memories From the Future, Psychoanalytic Dialogues, 25 (3): 309-324.

Benjamin, J. (1988). The bonds of love, London: Virago Press.

-----, (1995). Like Subjects, Love Objects, New Haven \& London Yale University Press. expresa. Este material es para uso científico y profesional exclusivamente y puede contener información clínica sensible. Los editores no se responsabilizan de los contenidos de los autores. Dirigir las consultas sobre derechos y autorizaciones a ceir@psicoterapiarelacional.es 
Bleichmar, H. (1997). Avances en Psicoterapia Psiconalítica. Barcelona: Paidos.

Bowlby, J. (1969). Attachment and Loss. Vol. 1. London: Hogarth Press.

Coderch, J. \& Plaza, A. (2016). Emoción y Relaciones Humanas. Madrid: Ágora Relacional - Colección Pensamiento Relacional, 15.

Garriga, C. (2015a). Una revisón de los conocimientos actuales sobre la sexualidad y el género I, www.aperturas.org $n^{\circ} 50$.

Garriga, C. (2015b). Una revisón de los conocimientos actuales sobre la sexualidad y el género II, www.aperturas.org $n^{\circ} 51$.

Gentille, J. (2016). Feminine Law, London: Karnac

Goldin, D. (2015). The Storied Self: The Search for Coherence Amidst Constant Cahange, Psychoanalytic Dialogues, 25(6) : 661-679.

Ringstrom, Ph. (2014). A Relational Psychoanalytic Approach to Couples Psychotherapy, New York: Routledge.

Stern, D. N. (1985). The Interpersonal World of the Infant. New York Basic Books.

Wallin, D. J. (2007). Attachment in Psychotherapy. New York: The Guilford Press.

Original recibido con fecha: 22-4-2017 Revisado: 30-8-2017 Aceptado: 30/09/2017 